\title{
A loucura maníaco-depressiva
}

\author{
Pelo Dr. Afrânio Peixoto \\ (Médico Alienista do Hospício Nacional \\ e membro da Sociedade Médico-psicológica de Paris)
}

Arquivos Brasileiros de Psiquiatria, Neurologia e Ciências Afins, Rio de Janeiro, n.1, 1905, p.33-46

\section{u U UUUU}

A concepção da loucura maníaco-depressiva é uma das sínteses gloriosas que marcam época nos fastos da psiquiatria. Deve-se ao Professor Emil Kraepelin. Entende-se por esta designação uma doença mental, ordinariamente hereditária, sobrevindo frequentemente no meio-dia da vida, manifestando-se por acessos isolados, subintrantes, intermitentes, de excitação ou depressão, puras ou combinadas, deixando intervalos de saúde, sem aparente lesão da inteligência.

Tanto vale dizer que aí ficam compreendidas todas aquelas consideradas espécies clínicas chamadas de mania, melancolia, loucura de dupla forma, periódica, alterna, atípica e suas variantes de intensidade e manifestação clínica. O que se supunha, tomando isoladamente a observação de um acesso, ou mesmo, mais ainda, a preponderância da fase de um acesso, como doença especial, é trazido ao rol de síndrome clínica, aparecendo só ou acompanhada, repetindo-se ou alternando, de modo a justificar o conceito, bem fundado, da loucura maníaco-depressiva.

Aos autores antigos não escapou a observação precursora desta síntese. Que da melancolia podia vir a mania, ou esta anteceder aquela, notaram, com mais ou menos insistência, Areteu da Capadócia, Hipócrates, Écio da Sicilia, Coelius Aurelianos, Alexandre de Tralles, Van Lon, Thomas Willis, Boerhaave, Marchand, Etmuller, Morgagni, Lorry, Rush; alternaram-se, mesmo, Pinel, Esquirol, Dubuisson, Guislain, Griesinger...; tomaram, finalmente, uma disposição cíclica, num tipo circular e de dupla forma, Falret pai, Bailarger, Kirn, Billod, Ritti..., até hoje, em que estas ideias dominam a psiquiatria, sendo escusado desfiar aqui o rosário de nomes que as referências atuais obrigariam. Convém notar, entretanto, que todas essas observações, à medida que se vêm aproximando da época atual, parecem ver, no caso, incidência de duas doenças diversas no mesmo indivíduo, enxerto nosológico apenas constatado, e nada mais. É justiça, pois, separar alguns nomes, em que o louvor se justifica, da previsão ou facilitação do conceito Kraepeliniano.

Areteu descreve acessos maníacos e melancólicos, substituindo-se e se confundindo até,

N.E. - Sobre este artigo, ver "A cena constituinte da psicose maníaco-depressiva no Brasil”, de Joel Birman, neste número de História, Ciências, Saúde - Manguinhos. 
traça-lhes uma explicativa patogênica e a esses casos julga de incuráveis pelas complicações e associações mórbidas que trazem. Alexandre de Tralles viu também na mania uma transformação exacerbada de melancolia, mas precisou muitos casos de alternância e periodicidade, comparados por ele à das febres intermitentes. Guislain verificou não só alternância e substituição da mania e da melancolia, mas até "uma fusão completa entre esses dois fenômenos, compreendendo a um tempo a tristeza e a violência". Não se pode aludir mais claramente a esses tipos, que Kraepelin veio a chamar Mischzustände. Morel, depois de se recusar a admitir a mania e a melancolia como elementos de uma classificação, senão as considerando como estados não permanentes, pois "são apenas sintomas de uma afecção nervosa eminentemente transformável", tampouco tolerou a mania e a melancolia circulares como variedade particular de alienação mental, notando que são os alienados hereditários "os que oferecem os caracteres mais notáveis de alternância, intermitência, periodicidade e de remissão". Ficam aí os germes da ideia de mania e melancolia - sintomas de uma afecção nervosa, eminentemente transformável, e das alienações hereditárias, nas quais acessos de excitação e depressão oferecem alternância, intermitência, periodicidade e remissão. Baillarger e Ritti, depois, estatuindo o grupo novo da loucura de dupla forma, agora compreendido na síntese de Kraepelin, demonstraram a existência de acessos complexos, dos quais a excitação e a depressão seriam fases imediata ou mediatamente juntas, rápida ou demoradamente associadas.

A observação de todos os fatos, mesmo variadíssimos, sobremaneira os mistos e aglutinados, a penetração no estudo de cada um deles em sua evolução, condenando o vezo de esquecer o doente e fazer dos sintomas concepções de doença, trouxe a Kraepelin a conclusão que existe uma espécie de enfermidade mental assente sobre um terreno de herança neuropática, que se manifesta por síndromes de excitação e depressão, isoladas, combinadas, misturadas ou alternadas, em intensidade, duração e disposição variáveis, passando sem lesão considerável da inteligência e se repetindo e recidivando através da vida: é a loucura maníaco-depressiva.

Etiologia - Um fato domina a etiologia da loucura maníaco-depressiva: é a tara familial, pesadíssima em neuropatia, as mais das vezes homeomorfa. É um ponto em que há algumas parciais discordâncias francesas (Magnan, Ballet... etc.), mas que uma observação mais demorada confirmará decerto. Não sei de outros doentes, não contando idiotas, imbecis e débeis, que possuam carga mais avantajada. A degeneração mental, as psiconeuroses (epilepsia, histeria, neurastenia) são quase sempre produções de um terreno que se preparou imediatamente nos antecedentes pelo álcool, pela sífilis, pelas privações, pelos excessos; a loucura maníacodepressiva vem principalmente de um terreno de há muito preparado nesse vezo e em que de preferência se cultiva essa doença mental. Quase, pois, se pode dizer que a loucura maníacodepressiva, se não vem de outra que tal, vem de um temperamento ou uma constituição fundamentalmente preposta à sua fundação: sob a influência de fatores que no meio fazem progredir a acumulação de disposições, o desequilíbrio se deu. Quando se conhece a evolução da doença, a intermitência mais ou menos espaçada, sem notável prejuízo da inteligência, e a conservação da lucidez desta em quase todas as variedades clínicas dos acessos (exceção feita apenas dos estados de inibição por confusão e estupor), uma dúvida pode assaltar o espírito: por que, sendo estes doentes tão consideravelmente preparados, existe uma tão grande resistência da inteligência à deterioração? Creio rebater a interpelação, lembrando o caso dos indivíduos originariamente precários, por exemplo, os de origem héctica, em que a tuberculose, que os 
assalta mais tarde, evolve torpidamente, tendendo a uma cronicidade que rarissimamente alcançam os que, sem nenhuma disposição, são agudamente atacados do mal. Como que uma pré-intoxicação conferiu uma tal ou qual imunidade relativa, fazendo as reações mais fracas e a evolução das doenças mais demorada. Em neuropatologia, mesmo, fatos semelhantes se averiguam: numa grande cópia de demências precoces não se encontram antecedentes hereditários: grande que seja a intensidade do mal produzido assentou-se rapidamente num terreno baldio; a degeneração ao invés, por muitos episódios que venha a ter, e para produzi-los, bastam causas insignificantes, bem se sabe, permite atravessar uma existência sem esbarrar na demência terminal. Dos casos que observei sob o aspecto da tara familial, a ilação é que os números de Kraepelin são exatos, se não ainda inferiores à realidade: 60 a 80\% dos maníaco-depressivos são hereditários. Weygandt vai adiante, marcando 90\%.

Disse que a herança era muitas vezes aqui homeomorfa: de fato, não só de doença, como, muitas vezes, da forma da doença. Conheço duas senhoras, filhas de uma outra, que, todas as três, têm tido, coincidindo com perturbações menstruais, gravidezes e menopausa da mais velha, acessos de excitação-depressão, absolutamente semelhantes. Um dos meus doentes é um maníacodepressivo, que tem em suas crises de excitação impulsos agressivos em que morde os indefesos próximos e, outras feitas, concepções paranoides em que inventa aparelhos, teorias, etc.; nas crises de depressão, choro, lástima, recusa de alimentos e impulsões suicidas. $\mathrm{O}$ avô materno tinha crises maníacas e era nestas ocasiões um querelante insuportável; a mãe era igualmente maníaca, tendo nos seus acessos paranoides que ia se casar com o rei D. Sebastião, dele se apresentando grávida e terminado por não querer mais viver, sitiofoba, em profunda depressão melancólica; uma tia, irmã gêmea da mãe, maníaca de acessos frequentes, é nestas ocasiões paranoide e tem impulsos em que morde aos que se avizinham; uma outra tia teve já dois acessos espaçados de mania e depressão. Um reparo curioso devo dizer aqui: a estigmatização degenerativa dos maníaco-depressivos não é tão acentuada como se poderia supor: muitos tenho visto que, tendo pais, tios, primos, irmãos, filhos, vesânicos de toda a ordem, revelam uma boa e conformada aparência, sem nenhum dos consideráveis indícios de degeneração. Talvez isto permitisse ajuizar a loucura maníaco-depressiva como o estado de desequilíbrio de uma, apenas, miopragia constitucional do sistema nervoso.

As causas ocasionais mais frequentes são as violências psíquicas de toda a ordem, as afetivas principalmente, só ou pelas consequências que nesses suscetíveis acarretam depois: tais os abusos alcoólicos, os excessos, as fadigas, as insônias, as privações de alimento. A gestação, o puerpério, a menopausa, as fadigas de estudo, o trabalho corporal, o coito imoderado etc., favorecem aquelas causas num terreno preparado.

A frequência da loucura maníaco-depressiva é de 10 a 15\% das admissões nos manicômios (Kraepelin). O número que encontrei no Brasil é inferior a este: em 10 anos (1894-1903) passaram pela observação do Hospício Nacional de Alienados 6.257 loucos, dos quais 413 ou 6,6\% eram maníaco-depressivos. Do gráfico especificado seguinte vê-se que, arbitrando em 5 a 10\%, temos aqui um limite exato de apreciação. 


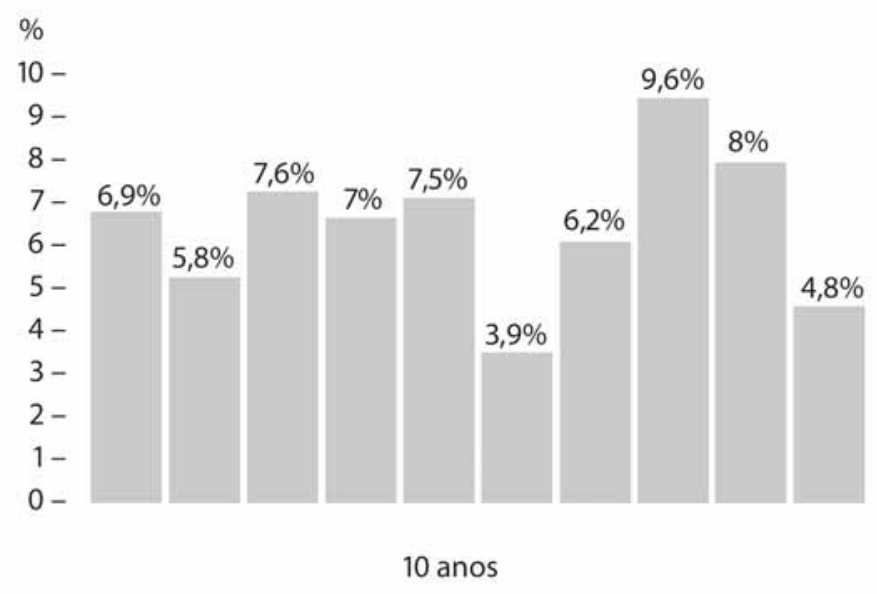

$1894,1895,1896,1897,1898,1899,1900,1901,1902$ e 1903

Total dos alienados: 6.257

424606624703709697614607616657

Loucura maníaco-depressiva: 413 29354749532637574931

Os sexos, ao contrário do observado na Europa, em que há um excesso de mulheres, apresentam no Brasil uma pequena diferença, para mais de maníaco-depressivos:

Em 2.426 mulheres alienadas, 151 ou 6,2\% eram maníaco-depressivas.

Em 3.831 homens alienados, 262 ou 6,8\% eram maníaco-depressivos.

A idade de predileção, segundo os números que obtive, é a que vai entre os 20 e os 40 anos, e que dá mais de metade (54\%), enquanto até os 20 é de pouco mais de um oitavo (13\%, e além dos 40 é de menos de um terço (32\%)). Kraepelin precisa o período que vai dos 20 aos 25 anos como a época de mais frequência da loucura maníaco-depressiva. Comparando os seus números e, principalmente os de Weygandt, com os brasileiros, apurei que até os 20 anos temos muito menos maníaco-depressivos, e, depois dos 40 anos, muito mais que os alemães.

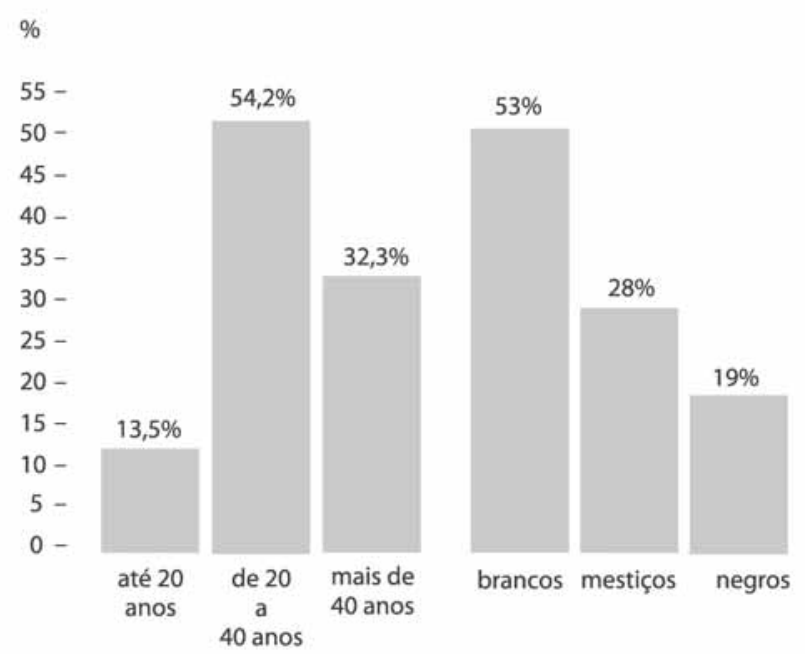


As raças contribuem diferentemente no Brasil para loucura maníaco-depressiva: mais de metade desses doentes é de brancos, mais de um quarto de mestiços, mais de um sexto de negros: o gráfico dá imediatamente a relação.

O seguinte gráfico permite conhecer a correlação da loucura maníaco-depressiva e das outras enfermidades mentais, reserva feita, entretanto, de que se trata de um serviço de homens em um hospício onde, a exceção do alcoolismo, são raros os casos agudos e abundam as demências.

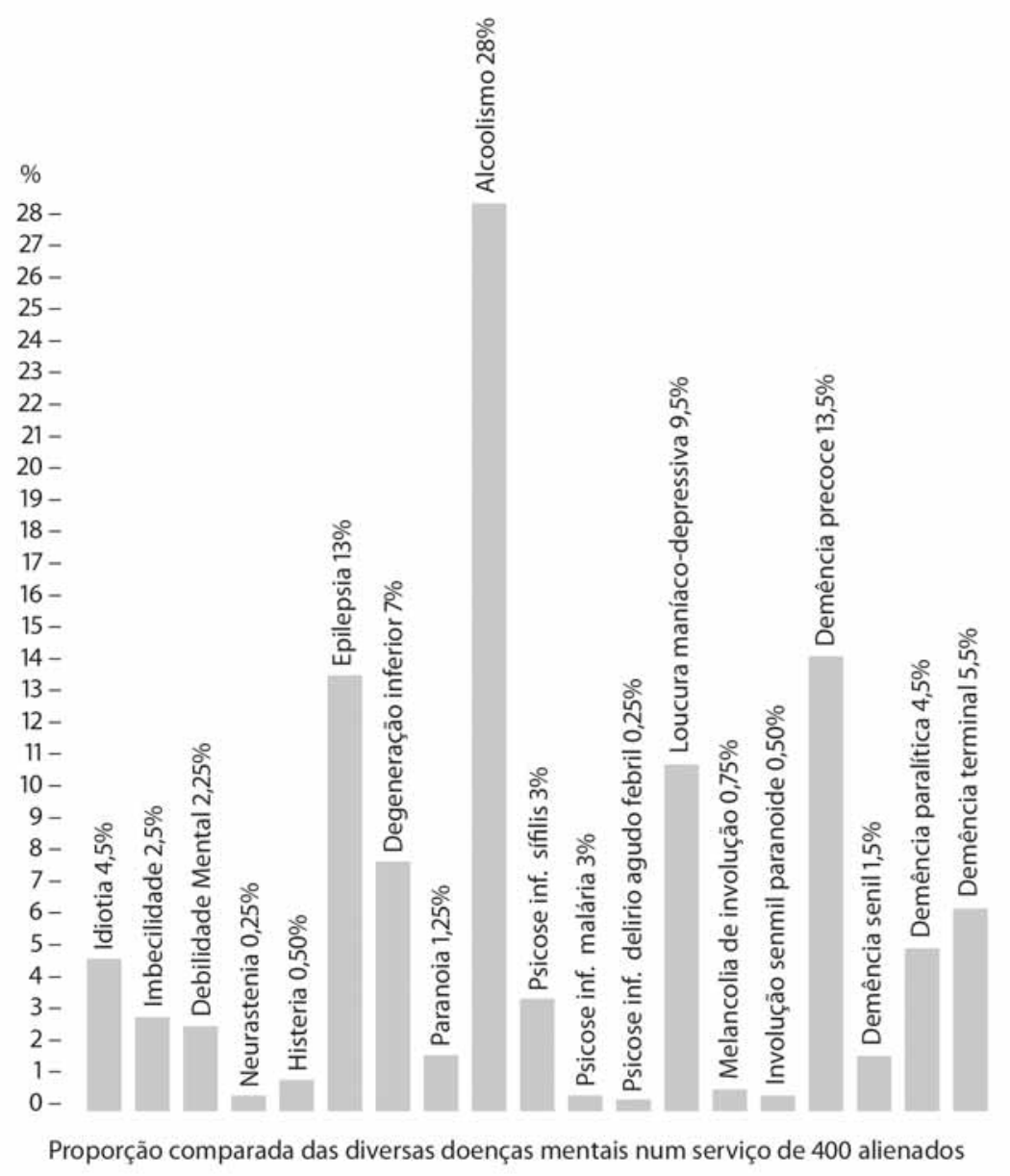

Patogenia - De Areteu e Meynert não se tem adiantado muito na explicativa como se processam as manifestações mórbidas da loucura maníaco-depressiva. "Enquanto o mal reside nos hipocôndrios e sua causa opera apenas nos arredores do diafragma e da bílis tem saída livre por cima e por baixo, o doente fica simplesmente melancólico; mas se essa causa age simpaticamente sobre o cérebro, o excesso de tristeza se muda em alegria e riso imoderados, que duram uma parte da vida. Os melancólicos tornam-se assim maníacos antes pelo progresso, que pela intensidade do mal..." Talvez esta frase última de Areteu, com uma pequena modificação, merecesse ser conservada. 
Muitos séculos depois, Billot não é mais elucidativo, explicando que o melancólico se excita "como para distender os seus nervos em estado de saturação de fluido", e ao invés o maníaco se deprime, porque na "fase de mania o sistema nervoso se desembaraçou de um excesso de inervação, indo a emissão além da quantidade excedente, e, por consequência, sucedendo a depressão à excitação".

Meyer quis explicar tudo por uma perturbação trófica vascular.

Meynert inferiu, da hiperemia encefálica, atribuída aos excessos de excitação, e da anemia dos mesmos centros, suposta nas fases de depressão, como patogênese, uma alteração periódica da inervação vascular: o prolongado espasmo vascular, produzido pela fadiga e promovendo as crises maníacas. Apenas Kraepelin obtempera a falta de demonstração das premissas e a inexplicabilidade, por este processo, dos estados mistos.

Weygandt alude vagamente aos atos fisiológicos de evolução periódica, como o sono, a menstruação, a impulsão sexual, o cio, a hibernação... Não conclui nada, nem mesmo nada poderia concluir, porque, de fato, se nestes casos "não se trata de uma lei física tão regular, como, por exemplo, a que rege os processos periódicos do sistema solar", tampouco se podem comparar as funções periódicas com os acessos da loucura maníaco-depressiva que, mesmo quando cíclica, é de uma periodicidade mais que relativa. Em uma palavra, no estado atual da fisiopsicologia normal e mórbida é puro empirismo uma patogênese desta ordem.

Sintomatologia - A loucura maníaco-depressiva é uma discenestesia. É fundamentalmente uma perturbação de tônus vital, de que é tradução aparente o humor: os fatos da inteligência, as alucinações, os erros sensoriais, as interpretações delirantes, lúcidas ou inconscientes, são secundárias. A aparência diversa dos casos extremos, da máxima exaltação à máxima depressão, não importam, porque um é o mecanismo de sua produção e apenas inversas as suas manifestações, e porque os fenômenos essenciais são constantes. É um erro supor que nos maníacos as funções físicas se exaltam e consoantemente se deprimem nos melancólicos: em uns, como em outros, elas estão abaixo da normalidade, muito embora a aparência favoreça nesta suposição aos primeiros. O perdulário de ação e inteligência, que parece ao maníaco, não é nem mais forte, nem mais inteligente. Toulouse verificou a dinamometria inferior mesmo nestes estados. Um dos meus doentes que tinha o receio de quebrar o dinamômetro, cumprindo a minha ordem de apertá-lo fortemente, alcançou um número irrisório para jactância. Féré apurou casos idênticos. A pressão sanguínea baixa nestes acessos e com ela o traçado do pulso (Pilcz). O peso do corpo diminui nas fases maníacas (Pilcz). A percepção ou atentação ativa é difícil e sempre inferior à normal (Kraepelin). A associação das ideias é enfraquecida e defeituosa (Kraepelin, Weygandt), e a memória perturbada não serve mais para dirigir a atividade num sentido útil (Féré). A aparente super atividade intelectual é uma simples manifestação do automatismo cerebral (Moreau de Tours).

A hiperideação maníaca é irreal: e nada mais falso do que esta expressão - fuga de ideias - que se tem perpetuado nas descritivas clínicas: não são verdadeiras ideias que a excitação maníaca produz; são apenas imagens verbais que se sucedem ininterrupta e irregularmente, ao sabor das associações mal feitas, quando não seja, nos casos extremos, de meras assonâncias. Um meu doente, pronunciando nessas ocasiões um número extraordinário de palavras, agrupa-as indistintamente sob o único critério da desinência homófona, assim, por exemplo: "sempre vive, em Ninive, nunca tive"; "matrimônio, de Santo Antônio, patrimônio do demônio". De um outro consegui reproduzir, na escrita, esta algaravia, que traslado textualmente: 
"Meu pai disse que eu era maluco, não tenho coisa alguma como advogado, porque saí para comprar encomendas, encontrei Major Quintino, fiz continência, sou oficial, não tenho sócios, sou da intendência prefeitural, nada tenho com sua estalagem na frente dum capoeira brasileiro, ás tocando uma ópera, dei com o pé no tabuleiro, esquentando os pés, em sete fogareiros, faça favor de emprestar esta chave, apertar aquela casa do paletó, ar de briga, prender em Pernambuco, com oficiais não se brinca, máxime com cantores, qualquer caixeiro, locomotiva a soprar fogo, chegou a polícia, a criança estava mexendo, cheguei pulei na certa, porque $V$. me deu três tiros ..." etc.

Estas circunstâncias todas provam apenas a aparente diversidade das manifestações maníacas com as melancolias no seu fundamento mesmo. Alterações profundas da cenestesia operadas num terreno preparado por causas, cujo modo de agir ainda nos escapa, determinam variados estados de humor, de estrutura comum, mas de aparência polimorfa. Seria ocioso descrever aqui essas síndromes clínicas da mania e da melancolia em toda sua gama de intensidade e feições; não é meu escopo, e é fácil preencher a lacuna em todos os livros da especialidade.

As formas clínicas da loucura maníaco-depressiva em sua aparente diversidade, têm tais conexões que constituem certamente o melhor argumento da síntese kraepeliniana. A primeira averiguação é a da raridade extrema dos tipos puros de excitação ou depressão.

Quem quer que possua alguma observação de alienados será logo impressionado pela ausência quase desses casos; a mania pura, clássica, então, existe apenas, e digo isto porque tive a fortuna de ver um caso em que nunca lobriguei a menor mistura depressiva. Agitados, loquazes, iracundos, agressivos, vi-os sempre terminarem suas cenas ou as interromperem pela emotividade fácil, as lágrimas, as queixas, as atitudes implorativas, as impulsões suicidas até; para recomeçarem logo após na excitação anterior.

Além da raridade dos acessos puros, há a notar a maior ainda dos acessos únicos. Hinrichsen apurou $4,7 \%$ de casos sem recidiva, além de 20 anos; Weigandt achou 4\%; Taalmann pouco menos, só encontrando 3 acessos únicos de mania em 107 maníacos examinados; Meyser só conseguiu 1,3\% observando 2.400 casos e ainda Kraepelin em 1.000 doentes nem um só logrou! Não conheço argumento mais convincente.

Os casos puros, de repetição, são igualmente muito raros: as chamadas manias e melancolias periódicas são tipos dos acessos comuns maníaco-depressivos, de predominância tal ou tal. Esta palavra é admiravelmente feita para designar a feição de maior cópia dos acessos maníacodepressivos. A observação mostra com efeito que o que correntemente se chama de acessos maníacos e acessos melancólicos são crises de excitação mesclada de fenômenos depressivos e vice-versa: são, portanto, uns e outros acessos de predominância maníaca ou de predominância depressiva. Não é aqui, entenda-se bem, o caso dos períodos de um acesso, soldados uns ao outro, segundo a expressão feliz de Ritti para a variedade de dupla forma; não é apenas uma ingerência habitual que forma o destaque do contraste, na exaltação na depressão. Esquematicamente os tipos clínicos da loucura maníaca e maníaco-depressiva se distribuíram assim: 


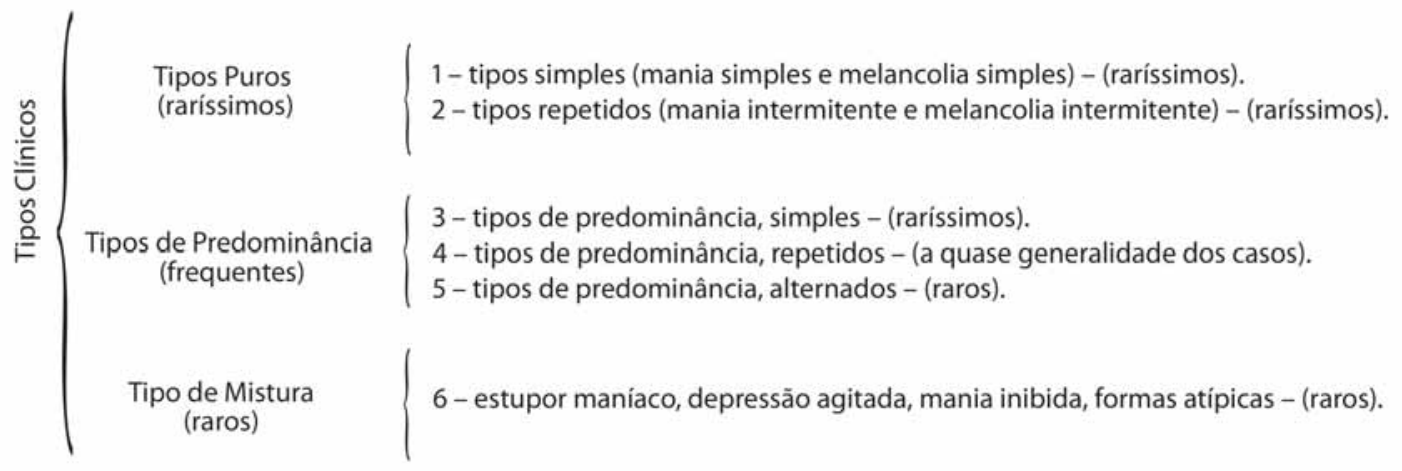

Como, descritivamente, algum interesse pode ser ligado às qualidades fundamentais da síndrome dominante, aqui vem de ocasião classificar esses vários estados em suas características clínicas:

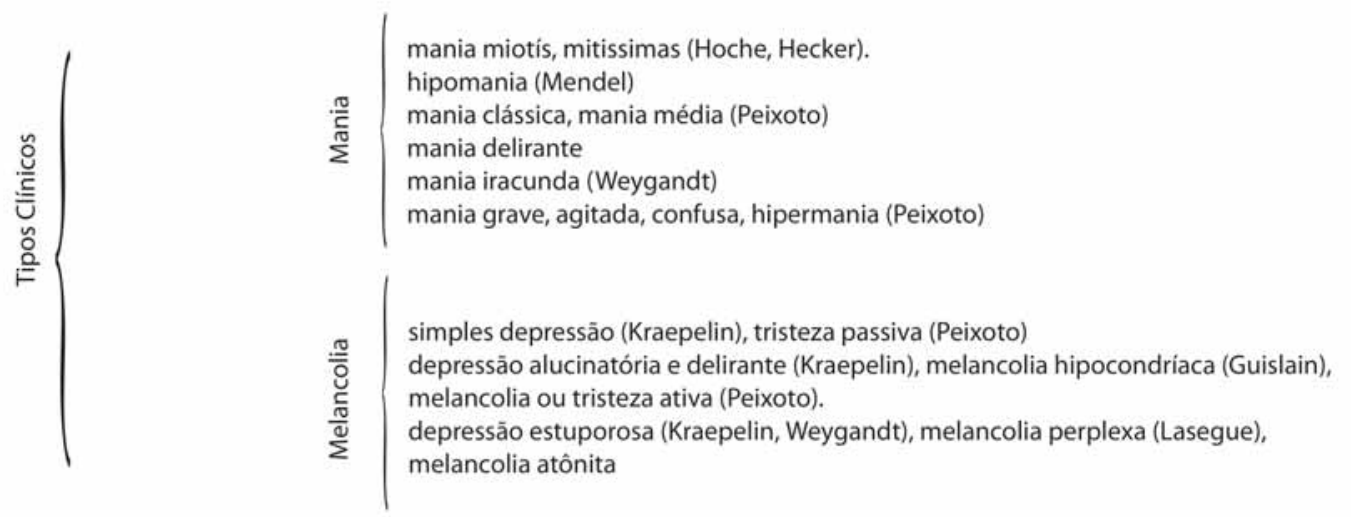

Para ilustrar esta questão dos tipos de predominância vêm de molde algumas estatísticas complementares às que já publiquei, páginas adiante. Em 413 maníaco-depressivos, exceção feita apenas de 4 casos distribuídos pelos outros tipos, 409 foram tipos de predominância, assim atribuídos; 291 casos (183 homens e 108 mulheres) de predominância melancólica, 118 (77 homens e 41 mulheres) de predominância maníaca. Em 100 alienados havia, pois, 1,8 maníacos e 4,7 melancólicos. A relação entre a predominância maníaca e a melancólica é, assim: de 1:2,46. Este resultado é curioso, porque algumas estatísticas estrangeiras dão sobrelevância à mania, ou porque as russas de Soukhanoff e Gannouchkine dão muito maior importância à melancolia.

Antes de fechar este capitulo. Um fato que importa é a indagação do estado mental ordinário intervalar dos acessos maníaco-depressivos: a psiquiatria francesa com Falret, Baillarger, Magnan, Ballet etc., permite supor a volta ao estado normal nesses intervalos, pelo menos quando espaçados, a alemã com Krafft-Ebing, Schule, Kraepelin, Weigandt põe restrições decididas, notando a permanência de algumas constantes de inferioridade hígida. Energia psíquica diminuída, irritabilidade exagerada, emotividade muito fácil, impulsividade muito pronta, aí estão fatos a toda hora certificáveis com que rebater a pretendida restituição ao normal. A observação destes mestres parece-me irrefutável, na clínica. O tônus abafado em uns, acendido em outros, estes 
suscetíveis e desconfiados, aqueles francos e inconvenientes, ainda não vi um que ficasse normal, se é que foram normais algum dia.

Diagnóstico - Quando não é o primeiro acesso que se tem de julgar, os precedentes, sua historia, os espaços intervalares, a observação rápida de paciente indicam imediatamente o diagnóstico. Se éo primeiro ataque, as dificuldades podem ser consideráveis. Mesmo levando em conta a instabilidade de humor, a agitação psicomotora, a incoerência de ação, a dispersão da atenção, a abundância e $o$ atropelo das imagens verbais, a raridade das alucinações, a conservação da lucidez e da orientação, nos estados exaltados e a tristeza ativa ou passiva, o retraimento psicomotor, a ausência da atividade espontânea, a concentração interna da atenção, a pobreza de ideias, a monotonia da expressão, a conservação da lucidez e da orientação nos estados depressivos, o diagnóstico não é sempre fácil. Afasto os casos de delírio alcoólico e de paralisia geral em que verificações somáticas podem imediatamente sustar as dúvidas. Duas ordens de perturbações mentais são de jeito a tornar vacilante o clínico: a demência precoce e a melancolia de involução. A demência precoce em suas formas hebefrênica, catatônica e até paranoide embaraçamos diagnósticos. A forma hebefrênica em muitos casos se parece tão de perto com a loucura maníacodepressiva que pensei em melhor qualificá-la de forma maníaco-depressiva da demência precoce. Aliás não foi pensando de outro modo que Kraepelin alude às formas depressivas da hebefrenia e Deny dá como outro nome forma maníaca. Bem que se diga ser a lesão da cenestesia muito menos aparente aqui, os erros sensoriais e as concepções delirantes muito mais frequentes e profundíssimas as lesões da consciência, é realmente muito custosa a distinção dos primeiros exames. O estupor catatônico e a melancolia atônita são separadas pelo negativismo, estereotipias, ticos, sugestibilidade, flexibilidade cérea do primeiro e uniforme retardamento psicomotor da outra. As delusões que conduz a exaltação maníaca e que tanto afeiçoam a melancolia hipocondríaca repousam exclusivamente quase sobre as alterações da cenestesia: as mesmas, monótonas, sempre voltadas para o indivíduo - na melancolia; variadas, brilhantes, incoerentes e a que os próprios doentes não conferem importância - na exaltação maníaca; as absurdas delusões da demência paranoica não tem aparência nem de umas, nem de outras e nem se instalam nos estados emocionais da expansão que são o fundo das delusões maníaco-depressivas. A melancolia de involução que Kraepelin precisamente separou das depressões melancólicas, que nos ocupam, sobrevém no período do retrocesso vital, sem inibição ou diminuição psicomotora e intelectual, sem as profundas lesões da cenestesia, mas com crises de angústia, ideias de negação, enormidade, autoacusação, delusões muito arraigadas e acentuada tendência para a demência. Muito caso, porém, de melancolia atônita e de mania confusa ou improdutiva pode afetar semelhança com outros imprecisos de melancolia de involução.

Prognóstico - O prognóstico se resume em saber que os acessos são transitórios, de duração variável, deixando espaços intervalares mais ou menos longos, nos quais residuam diferença de humor e ligeiras, mas a cada novo acesso mais acentuadas, lesões da inteligência.

Não é possível predizer o novo acesso, senão nas formas cíclicas, que não têm, entretanto, a regularidade teórica que se lhe tem emprestado. O maníaco-depressivo, pois, quando não está no desequilíbrio de seu acesso, está no equilíbrio instável da tendência para um outro acesso.

Tratamento - O internamento e o isolamento consecutivo são de magnífico efeito nas crises agudas em todos os casos. Os banhos permanentes, o leito, os sedativos, especialmente os bromados, 
os hipnagogos com vantagem o veronal, e sobre tudo a hioscina e a hiosciamina - estas camisas de força químicas - são muito úteis nos períodos de excitação. Os banhos frios, o leito, o ópio, a quinina, a estricnina, os purgativos, e os eupépticos visam os períodos de depressão.

Anatomia Patológica - A anatomia patológica é uma página ainda em branco a escrever na história da loucura maníaco-depressiva: os meios da apreciação são muito grosseiros e a vista científica do momento ainda muito pouco penetrante.

\section{$f F$}

